\title{
Atividades circenses na educação física: possibilidades e limites para a educação infantil
}

\author{
Circus activities in physical education: possibilities and limits for early childhood education
}

Actividades circenses en educación física: posibilidades y límites para la educación en la primera infancia

\author{
Adria Maria Messias ${ }^{1}$; Fernanda MORETo IMPOLCETTO ${ }^{2}$ \\ Universidade Estadual Paulista “Júlio de Mesquita Filho", UNESP, Rio Claro-SP, Brasil
}

\section{RESUMO}

O objetivo do estudo ${ }^{3}$ foi analisar as possibilidades e os limites que emergiram da implementação de uma Unidade Didática de Atividades Circenses. De natureza qualitativa, do tipo Pesquisa Participante, foi realizada com uma turma da $2^{\mathrm{a}}$ etapa da Educação Infantil. Como instrumento de construção dos dados utilizou-se o Diário de Campo, norteado por um roteiro para a realização dos registros observados durante as aulas. Os dados construídos foram tratados por meio da análise de categorias de codificação - codificação simples. Os principais resultados evidenciaram que: 1) diversos recursos (vídeos, músicas, fantasias) e materiais (de baixo custo ou recicláveis) possibilitaram a imersão dos alunos no universo circense; 2) algumas limitações (falta de uma estrutura física adequada, os eventos extras e a necessidade de tempo/quantidade maior de aulas) influenciaram o desdobramento das aulas, mas não prejudicaram o processo ensino e aprendizagem. Desse modo, confirmou-se a viabilidade e potencialidade do ensino das Atividades Circenses, nas aulas de Educação Física na Educação Infantil.

Palavras-chave: Educação Física Escolar. Educação Infantil. Atividades Circenses. Cultura Corporal de Movimento.

\begin{abstract}
The objective of the research was to analyze the possibilities and limits that emerged from the implementation of a Didactic Unit of Circus Activities. The qualitative research, based on the Participant Research method, it was carried out with a kindergarten students of Early Childhood Education. As an instrument for data construction, the Field Diary was chosen, based on a script for the realization of the records observed during the classes. The constructed data were treated through the analysis of coding categories - simple coding. The main results showed that: 1) several resources (videos, music, costumes) and materials (low cost or recyclable), allowed the immersion of students in the circus universe; 2) some limitations (lack of an adequate physical structure, extra events and the need for time/greater number of classes) influenced the unfolding of classes, but did not impair the teaching and learning process of Circus Activities. Thus, the feasibility and potentiality of the teaching of Circus Activities in physical education clas ses in Early Childhood Education were confirmed.
\end{abstract}

Keywords: Physical Education School. Early Childhood Education. Circus Activities. Body Culture of Movement.

\section{RESUMEN}

El objetivo de la investigación era analizar las posibilidades y límites que surgieron de la implementación de una Unidad Didáctica de Actividades Circenses. De carácter cualitativo, del tipo de encuesta de los participantes, se llevó a cabo con una clase de la 2a etapa de Educación Infantil Temprana. Como instrumento para la construcción de datos, se utilizó el Diario de Campo, basado en un script para la realización de los registros observados durante las clases. Los datos construidos fueron tratados a través del análisis de categorías de codificación - codificación simple. Los principales resultados mostraron que: 1) varios recursos (vídeos, música, vestuario) y materiales (de bajo costo o reciclables), permitieron la inmersión de los estudiantes en el universo circense; 2) algunas limitaciones (falta de una estructura física adecuada, eventos adicionales y la necesidad de tiempo/mayor número de clases) influyeron en el desarrollo de las clases, pero no afectaron el proceso de enseñanza y aprendizaje de las actividades circenses. Así, se confirmó la viabilidad y potencialidad de la enseñanza de las Actividades Circenses en las clases de educación física en Educación Infantil.

Palabras clave: Educación Física Escolar. Educación Infantil. Actividades de Circo. Cultura Corporal del Movimento.

\footnotetext{
${ }^{1}$ Mestre em Educação Física (ProEF/UFSCar). E-mail: adria.maria.m@gmail.com. ORCID: https://orcid.org/00000002-0532-6072.

${ }^{2}$ Professora do Instituto de Biociências da UNESP de Rio Claro e do Mestrado Profissional em Educação Física em Rede Nacional (ProEF), polo UNESP/Rio Claro. E-mail: fe_moreto@yahoo.com.br. ORCID: https://orcid.org/00000003-0463-0125.

${ }^{3}$ Pesquisa desenvolvida no Mestrado Profissional em Educação Física em Rede Nacional - ProEF, realizada durante as aulas de Educação Física em uma escola pública municipal do interior do Estado de São Paulo.
} 


\section{INTRODUÇÃO}

A primeira infância é o alicerce da vida humana, de características únicas e significativas para o desenvolvimento infantil em todos os seus aspectos, esse período corresponde à faixa etária em que se constitui uma etapa essencial da Educação Básica, a Educação Infantil (PORTUGAL, 2009; BRASIL, 2016; CARVALHO, 2019).

Entretanto, a regulamentação legal da Educação Infantil, como parte de uma educação formal, assim como a inserção da Educação Física, enquanto componente curricular obrigatório em toda a Educação Básica a partir da sua primeira etapa, é recente e percorreu um longo processo educativo, histórico, político e social (BRASIL, 1996).

Pelo fato de a Educação Infantil não se organizar de maneira disciplinar, como nas outras etapas da Educação Básica, nos documentos oficiais que a norteiam não se encontra uma referência direta à Educação Física e seus conteúdos específicos como conhecimento escolar. Porém, com vistas ao desenvolvimento integral da criança, eles estabelecem nos eixos estruturantes e objetivos de aprendizagem que, através das interações, das brincadeiras e do movimento (o qual constitui-se uma linguagem do desenvolvimento e da cultura humana) elas possam conhecer, relacionar, explorar e expressar-se corporalmente e com o mundo físico e sociocultural (BRASIL, 1998; BRASIL, 2013; BRASIL, 2018).

Compreende-se que é essencial, para o desenvolvimento e convívio social da criança, promover atividades adequadas às suas características e necessidades, do mesmo modo é incontestável a importância do professor de Educação Física, na Educação Infantil ${ }^{4}$, como o profissional capaz de garantir o desenvolvimento dos conteúdos de ensino relativos à especificidade da área.

Contudo, é necessário ampliar os conhecimentos sobre os conteúdos de ensino da Educação Física na Educação Infantil, pois observa-se uma escassez na produção literária que contemple práticas pedagógicas que colaborem efetivamente com o professor de Educação Física em sua atuação na Educação Infantil (GARANHANI, 2002) e entre os poucos trabalhos que são publicados, existe uma ênfase para o desenvolvimento motor da criança na faixa etária que integra esse ciclo de ensino. Para Simão (2005) "[...] publicações recentes têm ainda enfatizado a função da Educação Física na Educação Infantil como ‘auxiliadora' na alfabetização” (p. 167).

Mesmo que os documentos que norteiam a Educação Infantil, devido à integralidade do ensino, não se fundamentem nas práticas corporais desenvolvidas de acordo com as diversas manifestações da cultura corporal de movimento, essa já foi legitimada, para o componente Educação Física, pelos documentos que orientam os demais ciclos da Educação Básica, razão pela qual considera-se planejá-las também para a Educação Infantil.

Darido (2005) ao fazer referência aos conteúdos, declara que estes compreendem: "[...] conceitos, ideias, fatos, processos, princípios, leis científicas, regras, habilidades cognoscitivas, modos de atividade, métodos de compreensão e aplicação, hábitos de estudo, de trabalho, de lazer e de convivência social, valores, convicções e atitudes" (p. $65)$.

\footnotetext{
${ }^{4}$ De acordo com Rangel (2010) as pesquisas apontam o quanto as crianças são beneficiadas com a atuação de um profissional com formação e conhecimentos específicos ministrando atividades com conteúdos ligados ao movimento. No tocante a essa constatação a autora conclui que "[...] há necessidade de um educador com conhecimento sobre a importância do movimento por detrás das brincadeiras, não porque as mesmas não sejam ótimas para as crianças, mas para torná-la ainda melhores” (p. 2).
} 
É importante acrescentar que Soares et al. (1992) alertam sobre os elementos ligados à cultura corporal de movimento que não podem ser deixados de lado "[...] exteriorizadas pela expressão corporal: jogos, danças, lutas, exercícios ginásticos, esporte, malabarismos, contorcionismo, mímica e outros" (SOARES et al., 1992, p. 38).

Nessa perspectiva, reafirma-se a relevância e legitimidade das Atividades Circenses pois entende-se que o circo também é um componente da cultura corporal de movimento, que passou por um complexo processo histórico, político e social, com uma gama riquíssima de elementos que envolvem e favorecem a imaginação, o conhecimento e comportamentos de cooperação e coletividade, ou seja, geram ações pedagógicas possíveis de serem concretizadas no processo de ensino e aprendizagem.

Logo, pela variedade de saberes circenses que podem ser ensinados, devido à facilidade de sua adequação para práticas pedagógicas com fins educativos, pela diversidade de recursos e materiais possíveis de serem adaptados para oportunizar a todos os alunos, no ambiente escolar, novas e diferentes vivências nas práticas corporais circenses, considera-se as que as Atividades Circenses viabilizam/asseguram possibilidades de movimento, conhecimentos e valores que resultem em experiências satisfatórias.

Diante desse contexto, o objetivo do presente estudo foi analisar os limites e as possibilidades que se manifestaram da implementação de uma Unidade Didática (UD) ${ }^{5}$ para o ensino de Atividades Circenses nas aulas de Educação Física na Educação Infantil.

\section{Percurso metodológico}

Este estudo caracteriza-se por uma pesquisa de natureza qualitativa, com referencial teórico na Pesquisa Participante, onde o pesquisador participa, interage e acompanha todas as vivências com os participantes; observa as manifestações dos mesmos e as situações vividas; registra, de modo descritivo, os elementos observados e as análises e considerações que faz ao longo da participação nessa pesquisa (SEVERINO, 2007). Assim, diante dos elementos apresentados, acredita-se ser um método de pesquisa possível de ser desenvolvido no âmbito escolar.

$\mathrm{O}$ universo dessa pesquisa foram as aulas de Educação Física, do período matutino do ano 2019, de uma turma de 20 (vinte) alunos da $2^{\mathrm{a}}$ etapa (5 anos) da Educação Infantil de uma escola da rede pública municipal do interior do Estado de São Paulo.

O instrumento utilizado para a construção de dados foi o Diário de Campo (TRIVIÑOS, 1987), o qual recebeu uma estrutura/roteiro para que elementos significativos realizados nas aulas pudessem ser contemplados (BOGDAN; BIKLEN, 1994).

Seguindo uma classificação baseada no referencial teórico proposto por Duprat, Barragán e Bortoleto (2017), elaborou-se uma UD de Atividades Circenses. Constituída por 12 (doze) planos de aulas, onde optou-se por manter a estrutura metodológica de aula, que emana da própria prática pedagógica da professora/pesquisadora: (1) roda de conversa inicial; (2) desenvolvimento da aula; (3) roda de conversa final. Os conteúdos selecionados e os materiais utilizados foram flexibilizados e adaptados para a faixa etária da turma de $2^{a}$ etapa da Educação Infantil (5 anos), conforme o quadro a seguir:

\footnotetext{
${ }^{5}$ Considera-se como sendo a unidade didática, um conjunto de planos de aulas que são compostos por atividades estruturadas, numa sequência lógica e organizada, para atingir os objetivos de aprendizagem que se pretende alcançar no processo de ensino de determinado conteúdo.
} 
Quadro 1: Unidade Didática de Atividades Circenses adaptada etapa da Educação Infantil.

\begin{tabular}{|c|c|c|c|}
\hline didático & Blocos temáticos & Modalidades Circenses & $\begin{array}{l}\text { Adaptações/ } \\
\text { Instrumentos }\end{array}$ \\
\hline \multirow{3}{*}{ Manipulações } & \multirow{3}{*}{ De objetos } & \multirow{3}{*}{ Malabarismos } & Tule \\
\hline & & & Barangandã \\
\hline & & & Prato chinês (feltro) \\
\hline \multirow{2}{*}{ Equilíbrio sobre objetos } & $\begin{array}{l}\text { Equilíbrio do corpo em } \\
\text { movimento }\end{array}$ & Perna de pau & Pé de lata \\
\hline & $\begin{array}{l}\text { Equilíbrio do corpo em } \\
\text { superfícies instáveis }\end{array}$ & Corda bamba & $\begin{array}{l}\text { Prancha de equilíbrio e } \\
\text { Slackline }\end{array}$ \\
\hline \multirow{2}{*}{ Acrobacias } & Individuais & Solo & $\begin{array}{l}\text { Ponte, Vela, Paraquedas, } \\
\text { Avião e Cambalhota } \\
\text { para frente. }\end{array}$ \\
\hline & Grupo & Duplas, trios e quartetos & $\begin{array}{lrr}\begin{array}{l}\text { Algumas } \\
\text { adaptadas } \\
\text { apoios }\end{array} & \text { para } & \text { poses } \\
\text { seis }\end{array}$ \\
\hline Encenação & Palhaço & Diferentes técnicas e estilos & $\begin{array}{l}\text { Fantasias e brincadeiras } \\
\text { de imitações }\end{array}$ \\
\hline
\end{tabular}

Fonte: Adaptado de Duprat, Barragán e Bortoleto (2017).

Os dados construídos foram tratados por meio da análise de categorias de codificação - codificação simples - e foram consideradas cada uma das três etapas básicas para o processo de análise: 1. Leitura dos documentos; 2. Codificação dos materiais; 3. Categorização (BOGDAN; BIKLEN, 1994; FARIAS; IMPOLCETTO; BENITES, 2020).

Inicialmente realizou-se uma leitura minuciosa de todos os dados coletados das aulas no Diário de Campo, possibilitando uma identificação inicial em relação aos diferentes materiais.

Em seguida foi realizado o procedimento de etiquetagem das observações, onde buscou-se encontrar a frequência dos códigos em relação ao objetivo da pesquisa. Para tanto, o Diário de Campo foi submetido a quatro fases de análise dos dados (codificação), visando chegar à lista de códigos finais: iniciando com a transcrição do Diário de Campo (fase 1) e passando pelo processo de lapidação (fases 2, 3 e 4).

Foram encontrados 10 códigos, sendo que para a última etapa de análise dos dados (categorização) foi realizado o agrupamento dos códigos de acordo com suas similaridades. Desse modo, as unidades de códigos foram agrupadas em duas categorias: a) implementação da UD de Atividades Circenses: as possibilidades; b) implementação da UD de Atividades Circenses: alguns limites.

\section{RESULTADOS E DISCUSSÃo}

\section{IMPLEMENTAÇÃO DA UD DE ATIVIDADES CIRCENSES: AS POSSIBILIDADES}

Ao longo do processo de elaboração da UD de Atividades Circenses buscou-se utilizar alguns recursos que viabilizassem sua implementação e proporcionassem maior proximidade e associação dos alunos com o universo do Circo. Assim, foram 
selecionados e incluídos nas aulas para o desenvolvimento de alguns temas circenses: vídeos, músicas, fantasias, acessórios e outros materiais alternativos.

A utilização de vídeos infantis com o tema do circo, será o primeiro elemento indicado como possibilidade. Durante as rodas de conversas estabelecidas com os alunos, verificou-se que estes foram uma importante forma de ilustrar os conteúdos de ensino e contribuíram para a compreensão e aprendizagem dos alunos. O registro do Diário de Campo: "Reconheceram quando no vídeo aparece o malabarismo e o equilíbrio e com qual material são realizados" (DIÁRIO DE CAMPO, 10 de abril de 2019) demostra que houve a identificação e o reconhecimento dos alunos em relação aos elementos que tinham sido vivenciados.

Outra estratégia - o uso de músicas infantis com temas de circo - propiciaram um ambiente mais alegre e receptivo, favoreceram a imersão dos alunos no universo do Circo, além disso puderam ser aproveitadas para a elaboração de sequências de movimentos coreografados (proposta nas aulas de malabarismos com o tule e o barangandã) e também no dia do festival promovendo mais autenticidade na apresentação. Encontrados em sites da internet ${ }^{6}$ (vídeos e músicas), são exemplos de suportes pedagógicos economicamente viáveis, de fácil acesso para o professor e que servem para enriquecer e fomentar o processo de ensino e aprendizagem.

Pode-se afirmar que outro recurso utilizado que encantou os alunos foram as fantasias e acessórios, alguns da própria unidade de ensino e outros adquiridos para a pesquisa. No que diz respeito a esses recursos observou-se que: "Os materiais utilizados e as fantasias foram fundamentais para o envolvimento destas na atividade proposta" (DIÁRIO DE CAMPO, 02 de abril de 2019). Nessa faixa etária, os alunos costumam ter algumas fantasias, máscaras e outros objetos para brincar em casa, portanto, torna-se uma estratégia viável verificar se eles têm algum material que possa ser utilizado para brincar de Circo e a possibilidade de trazerem para usar durante a aula.

Sobre a utilização de diferentes materiais para tematizar as aulas de Atividades Circenses, constatou-se a possibilidade de adaptação de alguns objetos, de baixo custo ou recicláveis, também viabilizaram o processo de ensino e aprendizagem.

Alguns foram trazidos pelos alunos para a escola (como por exemplo: latas utilizadas na construção dos pés de latas), outros foram disponibilizados pela própria escola (como por exemplo: TNT utilizado na construção dos barangandãs) e outros constavam dos materiais utilizados nas aulas de Educação Física, como colchonetes, cordas grandes (que podem, a critério do professor, ser substituídas por barbantes, e prancha de equilíbrio - que pode ser trocada pelo banco sueco). Além disso, notou-se também que a opção de utilizar cores variadas para confeccionar os materiais (tule, barangandã e prato chinês) produziu o efeito visual desejado, despertou atenção, envolveu os alunos e tornou o ambiente mais alegre e festivo.

A exceção foi o slackline, material indisponível na rede de ensino e que foi utilizado para a aula, cuja proposta era vivenciar a corda bamba ${ }^{7}$. Munhoz e Ramos (2008) sugerem que os materiais de valores econômicos mais altos, devem ser solicitados à própria unidade escolar para aquisição, pois o investimento é recompensado quando se considera sua durabilidade. Verificou-se que o uso de materiais adaptados constava tanto nas sistematizações de propostas pedagógicas de

\footnotetext{
${ }^{6}$ Vasques (2017) nos aponta que, apesar de serem fontes nem sempre confiáveis, os sites e vídeos, podem contribuir consideravelmente na elaboração de propostas pedagógicas e tornarem-se um estímulo inicial para novos saberes científicos.

${ }^{7}$ Essa aula foi ministrada por um professor do Departamento de Esporte do Município, que possuía o equipamento slackline, conhecimento e experiência necessários para proporcionar a vivência, a convite da professora/pesquisadora da Unidade Escolar.
} 
Atividades Circenses na Educação Infantil (DIAS, 2009; CORSI, 2016; VASQUES, 2017), quanto em outros estudos que abordaram tais atividades no âmbito escolar nas demais etapas da Educação Básica: no Ensino Fundamental I (MUNHOZ; RAMOS, 2008); no Ensino Fundamental II (SIMÕES; GOMES; OLIVEIRA, 2008; SIMON; KRONBAUER, 2013).

Desse modo, considera-se que o custo econômico dos equipamentos e materiais que englobam as Atividades Circenses não serve como justificativa para o não desenvolvimento das mesmas em âmbito escolar.

Constatou-se que os diversos recursos e materiais utilizados foram fundamentais para a implementação da UD, proporcionaram uma maior motivação e envolvimento dos alunos aproximando-os do universo circense e potencializando o processo ensino aprendizagem de Atividades Circenses.

\section{IMPLEMENTAÇ̃̃O DA UD DE ATIVIDADES CIRCENSES: ALGUNS LIMITES}

Ao longo da implementação da UD de Atividades Circenses alguns imprevistos que ocorreram, decorrentes de diferentes razões, influenciaram o desenvolvimento das aulas e tornaram necessário o uso de algumas estratégias que auxiliassem nas intervenções pedagógicas.

Observou-se, pelos registros do Diário de Campo, que o principal fator limitante se tratava da estrutura da escola para as aulas de Educação Física: "Nesse dia o pátio foi lavado e não pode ser utilizado para a aula, como no campo a grama ainda estava com muito orvalho, a aula foi realizada em um espaço cimentado, porém descoberto" (DIÁRIO DE CAMPO, 10 de abril de 2019). Assim, apesar de contar com vários e amplos espaços na unidade escolar, o fato de não se ter um local próprio e adequado para a realização das aulas de Educação Física, gerou em diversos momentos contratempos e a necessidade de reorganizar a aula.

Verificou-se também que, a depender da temática da aula, condições de tempo, como o vento (para a realização dos malabares com o tule) e as restrições em relação ao ambiente em que as aulas são realizadas (ao ar livre ou local com pouco espaço) também podem interferir na realização das atividades.

Alguns estudos apontam problemas semelhantes com relação à infraestrutura escolar inadequada para a realização das aulas de Educação Física (FARIAS, 2018; DE LUCCA, 2019), fato que por vezes dificulta o trabalho pedagógico do professor.

Outro fator identificado diz respeito ao acontecimento de eventos "extras", que além de não constarem no calendário escolar não são comunicados previamente, e em algumas ocasiões implicam diretamente nas aulas de Educação Física na escola, promovem dificuldades ou até mesmo impossibilitam a continuidade de algumas atividades, a exemplo do recorte do registro do Diário de Campo: "A aula foi interrompida por conta de um evento que aconteceria na escola, a chegada do coelho para a entrega da lembrancinha e dos ovos de páscoa para as crianças e não foi realizada duas atividades planejadas" (DIÁRIO DE CAMPO, 17 de abril de 2019), tendo sido estas finalizadas no dia de aula seguinte.

Percebeu-se que fatores como o tempo/quantidade de aulas e a segurança ${ }^{8}$ podem ser limitantes para o desenvolvimento das Atividades Circenses. A limitação quanto ao tempo para que se cumprisse o planejamento pré-estabelecido, também mereceu destaque nos estudos de Simon e Kronbauer (2013). Considerando-se as vivências

\footnotetext{
${ }^{8}$ A segurança dos alunos é uma preocupação constante na prática pedagógica do professor de Educação Física, pois o risco de algum acidente é inerente a qualquer tipo de atividade, seja de conteúdos de ensino das Atividades Circenses ou qualquer outro da cultura corporal de movimento e independente de qual nível da Educação Básica será desenvolvido.
} 
propostas, as dificuldades que os alunos possam apresentar e os imprevistos que possam ocorrer, uma hora/aula de 50 minutos acaba sendo insuficiente. Portanto, programar mais aulas envolvendo o mesmo tema é algo que deve ser cogitado.

Durante a implementação da UD de Atividades Circenses, o olhar atento da professora/pesquisadora, sua presença constante na execução dos movimentos pelos alunos e o conhecimento dos materiais utilizados, inclusive para a segurança, garantiram que nenhum incidente acontecesse. Segundo Munhoz e Ramos (2008) “[...] apesar de 'novos' e 'diferentes', esses conteúdos não podem ser trabalhados de qualquer forma, é necessário que o professor de Educação Física busque informações que envolvam o conteúdo específico e o próprio processo pedagógico do que já foi realizado" (p. 280).

Assim, constatou-se que apesar de algumas limitações ou dificuldades, o desenvolvimento de Atividades Circenses na Educação Infantil é viável e precisa ser incorporado/concretizado no processo de ensino e aprendizagem dos conteúdos da Educação Física Infantil.

\section{CONSIDERAÇÕES FINAIS}

O presente estudo teve a finalidade de analisar os limites e as possibilidades que se manifestaram da implementação de uma UD para o ensino de Atividades Circenses nas aulas de Educação Física na Educação Infantil.

Foram realizadas algumas etapas metodológicas para o cumprimento do objetivo proposto e nos resultados verificou-se que: 1) diversos recursos e materiais viabilizaram e proporcionaram tanto a implementação da UD de Atividades Circenses quanto uma maior proximidade e associação dos alunos com o universo circense, não havendo justificativa para sua não inclusão nas aulas de Educação Física na Educação Infantil; 2) algumas limitações foram encontradas ao longo da implementação da UD de Atividades Circenses e que apesar de influenciarem o desdobramento das aulas não impossibilitaram que estas acontecessem.

Como possibilidades evidenciou-se que os vídeos, as músicas, as fantasias e os acessórios utilizados, favoreceram a imersão dos alunos no mundo do circo e que a utilização de materiais de baixo custo ou recicláveis, com a possibilidade de os alunos participarem da sua construção, serviram para enriquecer e viabilizar o processo de ensino e aprendizagem.

É oportuno referir que, alguns materiais estão disponibilizados entre os equipamentos das aulas de Educação Física e mesmo aqueles indisponíveis, apesar do seu alto custo econômico, há que se considerar a possibilidade de aquisição pela unidade escolar devido a sua durabilidade.

Em se tratando dos fatores limitantes, o principal deles é a realidade escolar de muitos professores de Educação Física, que se manifesta na falta de uma estrutura física adequada para as aulas, que como consequência gerou em diversos momentos outros contratempos como a transição de locais, a exposição às intempéries, a restrição quanto ao espaço para realizar as vivências e as atividades planejadas para as aulas. Além disso, imprevisibilidades ocorreram também em relação a alguns eventos "extras" que aconteceram sem comunicação prévia, os quais impossibilitaram até mesmo de continuar a aula naquele momento.

No desenvolvimento de algumas atividades planejadas, o tempo/quantidade de aulas foram fatores limitantes, dadas às dificuldades que os alunos apresentaram e aos imprevistos que aconteceram, o que apontou para a necessidade de um 
tempo/quantidade maior de aulas para uma melhor vivência e aprendizagem dos alunos, o que se configura como um limite da presente pesquisa.

Vale ressaltar que essas questões descritas anteriormente não prejudicaram o processo de ensino e aprendizagem e, que todos os cuidados previamente tomados visando a segurança dos alunos na realização das Atividades Circenses, resultaram no fato de que nenhum incidente/acidente ocorreu.

Assim, diante de todos os resultados ora apresentados, espera-se que os aspectos analisados nesta pesquisa sejam relevantes para futuras investigações, pois entende-se que pela escassez de estudos na área, é necessário e significativo o aprofundamento de novas intervenções. Que as considerações aqui apresentadas possam trazer aportes para referenciar, coadjuvar e influenciar novas propostas de pesquisas e intervenções da Educação Física na Educação Infantil, uma vez que foram apresentados os limites e as possibilidades alcançadas, por meio das Atividades Circenses.

\section{REFERÊNCIAS}

BOGDAN, R.; BIKLEN, S. Investigação qualitativa em educação: uma introdução à teoria e aos métodos. Porto: Porto Editora, 1994.

BRASIL. Ministério da Educação e do Desporto. Base Nacional Comum Curricular. A Etapa da Educação Infantil. Brasília, 2018. Disponível em: http://basenacionalcomum.mec.gov.br/abase/\#infantil. Acesso em: 02 jul. 2018.

BRASIL. Estatuto da Primeira Infância. Lei $n^{\circ} 13.257$ de 08 de março de 2016. Disponível em: http://www.planalto.gov.br/ccivil_03/_Ato2015-2018/2016/Lei/L13257.htm. Acesso em: 10 jul. 2019.

BRASIL. Ministério da Educação. Secretaria de Educação Básica. Diretrizes Curriculares Nacionais da Educação Básica. Brasília, 2013. Revisão das Diretrizes Curriculares Nacionais para a Educação Infantil, p.102-142.

BRASIL. Ministério da Educação e do Desporto. Secretaria de Educação Fundamental. Referencial curricular nacional para a educação infantil. Brasília: MEC/SEF, 1998. 3v. Disponível em: http://portal.mec.gov.br/seb/arquivos/pdf/rcnei_vol1.pdf. Acesso em: 01 jul. 2018.

BRASIL. Lei de Diretrizes e Bases da Educação Nacional. Lei no 9394 de 20 de dezembro de 1996. Disponível em: http://www.planalto.gov.br/ccivil_03/LEIS/19394.htm. Acesso em 28 jun. 2018.

CARVALHO, M. T. V. Primeira infância: a etapa mais importante na vida da criança. UNOi educação. 2019. Disponível em: <https://unoieducacao.com/2019/03/14/primeira-infancia-a-etapa-mais-importantena-vida-da-crianca>. Acesso em: 12 jul. 2019.

CORSI, L. M. A Educação Física na Educação Infantil: uma proposta interdisciplinar de atividades circenses. 2016. 109 p. Trabalho de Conclusão de Curso (Graduação em Educação Física) - Faculdade de Educação Física, Universidade Estadual de Campinas, Campinas, dez. 2016. Disponível em: http://www.bibliotecadigital.unicamp.br/document/?code=000448524. Acesso em: 07 jul. 2019.

DARIDO, S. C. Os conteúdos da Educação Física na Escola. In: DARIDO, S.C.; RANGEL, I.C.A. Educação Física na Escola: implicações para a prática pedagógica. Rio de Janeiro: Guanabara Koogan, 2005. p. 64-79.

DE LUCCA, M. H. S. Tic e Sport Education: uma proposta pedagógica para o ensino dos saberes conceituais técnicos do handebol no Ensino Médio. 2019. Dissertação (Mestrado em Desenvolvimento Humano e Tecnologias) - Instituto de Biociências, Universidade Estadual Paulista Júlio de Mesquita Filho, Rio Claro, 2019. Disponível em: http://hdl.handle.net/11449/181388. Acesso em: 16 fev. 2020.

DIAS, L. C. Arte circense no ensino infantil: reflexões sobre uma proposta. 2009. 109 p. Trabalho de Conclusão de Curso (Graduação em Educação Física) - Faculdade de Educação Física, Universidade 
Adria Maria Messias; Fernanda Moreto Impolcetto

Estadual de Campinas, Campinas, dez. 2009. Disponível em: http://www.bibliotecadigital.unicamp.br/document/?code=000448524. Acesso em: 08 jun. 2019.

DUPRAT, R. M.; BARRAGÁN, T. O.; BORTOLETO, M. A. C. Atividades circenses. In: GONZALEZ, F. J.; DARIDO, S. C.; OLIVEIRA, A. A. B. Ginástica, dança e atividades circenses. Maringá: Editora da UEM, 2017. p. 119-157. (Coleção práticas corporais e a organização do conhecimento).

FARIAS, A. N. Livro didático e as Tic: Limites e possibilidades para as aulas de Educação Física do Município de Caucaia/CE. 2018. Dissertação (Mestrado em Desenvolvimento Humano e Tecnologias) Instituto de Biociências, Universidade Estadual Paulista Júlio de Mesquita Filho, Rio Claro, 2018. Disponível em: http://hdl.handle.net/11449/152598. Acesso em 16 fev. 2020.

FARIAS, A.N; IMPOLCETO, F.M; BENITES, L.C. A análise de dados qualitativos em um estudo sobre educação física escolar: o processo de codificação e categorização. Revista Pensar a Prática, v. 23, p. 120, 18 set. 2020. Disponível em: https://www.revistas.ufg.br/fef/article/view/57323/35350. Acesso em: 21 set. 2020.

GARANHANI, M. C. A educação física na escolarização da pequena infância. Revista Pensar a Prática, v. 5, p. 106-122, jul. / jun. 2002. Disponível em https://revistas.ufg.emnuvens.com.br/fef/article/view/49/46. Acesso em: 20 dez. 2019.

MUNHOZ, J. F; RAMOS, G. N. S. O circo nas aulas de Educação Física: sua aplicação em uma escola pública no Estado de São Paulo. In: SEMINÁRIOS DE ESTUDOS EM EDUCAÇÃO FÍSICA ESCOLAR, 2., 2008, São Carlos. Anais [...]. São Carlos: CEEFE/UFSCar, 2008. p. 255-292. Disponível em: http://www.eefe.ufscar.br/pdf/2a/munhoz.pdf. Acesso em: 04 mar. 2019.

PORTUGAL, G. Desenvolvimento e Aprendizagem na Infância. In: Conselho Nacional de Educação (org.). Relatório do estudo: a Educação das crianças dos 0 aos 12 anos. Lisboa: Ministério da Educação, 2009. p. 33-67. Disponível em: http://www.cnedu.pt/content/antigo/files/pub/EducacaoCriancas/5Relatorio.pdf. Acesso em: 03 ag. 2019.

RANGEL, I. C. A. Conhecendo o Ensino da Educação Física na Infância. In: RANGEL, I. C. A.; DARIDO, S. C. Educação Física na Infância. Rio de janeiro: Guanabara Koogan, 2010. p. 4-15.

SEVERINO, A. J. Metodologia do trabalho científico. 23. ed. São Paulo: Cortez, 2007.

SIMÃO, M. B. Educação Física na Educação Infantil: refletindo sobre a "hora da Educação Física". Motrivivência, v. $17, \quad$ n. $25, \quad$ p. $163-172$, dez. 2005. Disponível em: https://periodicos.ufsc.br/index.php/motrivivencia/article/view/4701/3879. Acesso em: 17 out. 2019.

SIMÕES, M. C.; GOMES, R. F.; OLIVEIRA, R. C. S. Atividades circenses: limites e possibilidades nas aulas de educação física escolar. 2008. 32 p. Monografia (Graduação em Educação Física) - Escola Superior São Francisco de Assis, Santa Teresa, nov. 2008. Disponível em: http://www.educadores.diaadia.pr.gov.br/arquivos/File/2010/artigos_teses/EDUCACAO_FISICA/monogr afia/Atividades_circenses.pdf. Acesso em: 16 out. 2019.

SIMON, J. M.; KRONBAUER, G. A. Atividades circenses: possibilidade de significação e representação do movimento nas aulas de educação física. In: PARANÁ. Os desafios da escola pública paranaense na perspectiva do professor. Paraná: Secretaria da Educação, 2013. p. 1-15. (Cadernos PDE, v. 1). Disponível

em: http://www.diaadiaeducacao.pr.gov.br/portals/cadernospde/pdebusca/producoes_pde/2013/2013_unicentr o_edfis_artigo_jackeline_maria_simon.pdf. Acesso em: 15 out. 2019.

SOARES, C. L.; TAFFAREL, C. N. Z.; VARJAL, E.; CASTELlANI FILHO, L.; ESCOBAR, M. O., BRACHT, V. Metodologia do ensino de educação física. São Paulo: Cortez, 1992.

TRIVIÑOS, A. N. S Introdução à pesquisa em Ciências Sociais: a pesquisa qualitativa em educação. São Paulo: Atlas, 1987. 
VASQUES, H. C. Atividades Circenses: proposta pedagógica para a Educação Infantil. 2017. Trabalho de Conclusão de Curso (Graduação em Licenciatura em Educação Física) - Universidade Estadual de Campinas, Campinas, 2017. Disponível em: http://www.bibliotecadigital.unicamp.br/document/?code=000992199. Acesso em: 04 jan. 2019.

Recebido em: 12 dez. 2020. Aprovado em: 10 abr. 2021. 